INSTITUTO LUTERANO DE ENSINO SUPERIOR DE ITUMBIARA - GOIÁS CURSO DE ADMINISTRAÇÃO

JANAINA GONÇALVES BORGES

A IMPORTÂNCIA DA RESPONSABILIDADE SOCIAL NA ALAVANCAGEM DA MARCA DAS EMPRESAS

Itumbiara-GO

2020 
JANAINA GONÇALVES BORGES

\title{
A IMPORTÂNCIA DA RESPONSABILIDADE SOCIAL NA ALAVANCAGEM DA MARCA DAS EMPRESAS
}

\author{
Trabalho de conclusão de Curso \\ apresentado ao Curso de Administração \\ do Instituto Luterano de Ensino Superior de \\ Itumbiara - ILES/ULBRA, como requisito \\ para obtenção do título de Bacharel em \\ Administração.
}

Orientadora: Sandra Marques Borges. 
JANAINA GONÇALVES BORGES

\title{
A IMPORTÂNCIA DA RESPONSABILIDADE SOCIAL NA ALAVANCAGEM DA MARCA DAS EMPRESAS
}

\begin{abstract}
Trabalho de conclusão de Curso apresentado ao Curso de Administração do Instituto Luterano de Ensino Superior de Itumbiara - ILES/ULBRA, como requisito para obtenção do título de Bacharel em Administração.
\end{abstract}

Orientadora: Sandra Marques Borges.

Data da apresentação:

Sandra Marques Borges

Nome - Titulação - Instituição

Nome - Titulação - Instituição 
Dedico este trabalho a todos que estão envolvidos na pesquisa, principalmente aqueles que fazem parte do curso de administração. 


\section{AGRADECIMENTOS}

Agradeço primeiramente a Deus que permitiu que eu concluísse essa etapa da vida.

Agradeço a todos que estão envolvidos, nesta pesquisa, agradeço a coordenadora Sandra Borges que me orientou durante a elaboração do trabalho.

Agradeço a todos da banca de avaliação, aos alunos presentes no dia da apresentação da pesquisa. 


\section{EPÍGRAFE}

"Ser socialmente responsável não se restringe ao cumprimento de todas as obrigações legais, implica em ir além, por meio de um maior investimento em capital humano no ambiente e nas relações com outras partes interessadas e comunidades locais." 


\section{RESUMO}


No mercado atual, a preocupação com questões sociais e ambientais tem aumentado cada vez mais, de modo que muitas empresas não têm somente prezado o lucro, mas também a sustentabilidade e o meio social. Dessa forma, muitas dessas empresas têm utilizado de ações de responsabilidade social, abraçando uma causa e se diferenciando em meio ao mercado empresarial. Nesse sentido, este estudo tem como objetivo geral refletir a respeito da importância da responsabilidade social corporativa na alavancagem de marcas empresariais. Tal objetivo é concluído abordando os seguintes pontos: conceituação da responsabilidade social corporativa; apresentação da construção de uma marca; e demonstração de ações de responsabilidade social nos contextos internos e externos às empresas. Para a elaboração deste estudo utilizou-se a metodologia de pesquisa bibliográfica, a qual baseou-se em estudos científicos provenientes das seguintes bases de dados presentes na Web: Google Scholar, SciELO e Scopus. Por fim, conclui-se que a responsabilidade social corporativa tem um grande poder de alavancagem das marcas empresariais, demonstrando que a empresa que faz uso deste meio de maneira correta, abraçando de fato a causa, conseguirá obter um maior destaque no mercado, obtendo bons retornos financeiros.

Palavras-chaves: Responsabilidade social corporativa. Alavancagem de marca. Valor da marca. 
In the current market, the growing concern about social and environmental issues has increased more and more, so that many companies have not only valued profit, but also sustainability and the social environment, thus, many of these companies have used actions social responsibility, embracing a cause and differentiating itself in the business market. Thus, this study has the general objective of talking about the importance of corporate social responsibility in leveraging corporate brands. This objective is concluded by addressing the following points: conceptualization of corporate social responsibility; presentation of building a brand; and demonstration of social responsibility actions in the internal and external contexts of the companies. For the preparation of this study, the bibliographic research methodology was used, which was based on scientific studies from the following databases present on the Web: Google Scholar, SciELO and Scopus. Finally, it is concluded that corporate social responsibility has a great power to leverage corporate brands, demonstrating that the company that makes use of this medium in a correct way, actually embracing the cause, will be able to obtain a greater prominence in the market, obtaining good financial returns.

Key words: Corporate Social Responsibility; Brand Leverage; Brand Value. 
Tabela 1: Estudos utilizados na discussão 28 


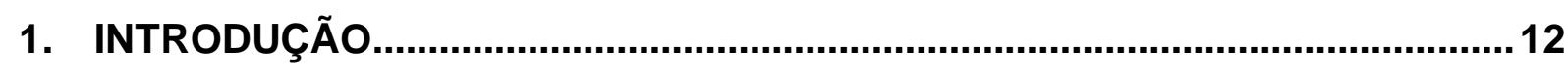

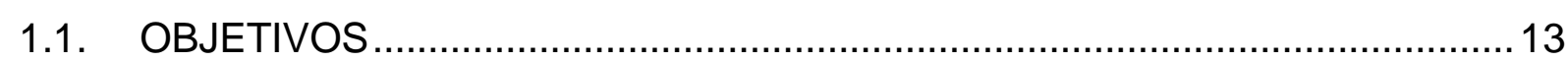

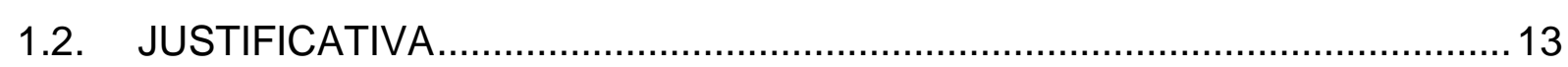

2. REVISÃO BIBLIOGRÁFICA ..................................................................14

2.1. DEFINIÇÃO DE RESPONSABILIDADE SOCIAL CORPORATIVA ................14

2.2. FATORES QUE INFLUENCIAM A RESPONSABILIDADE SOCIAL...............15

2.3. RESPONSABILIDADE SOCIAL CORPORATIVA COMO RECURSO PARA

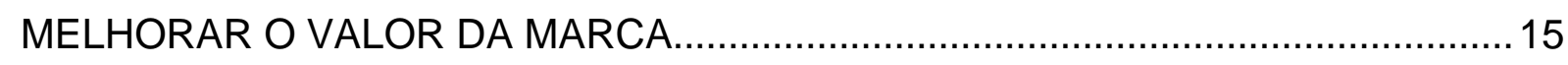

2.3.1. Contribuição para o conhecimento da marca .........................................16

2.3.2. Reforço da imagem da marca .............................................................16

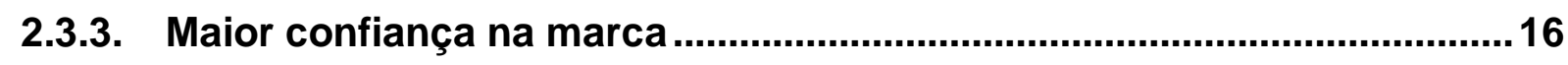

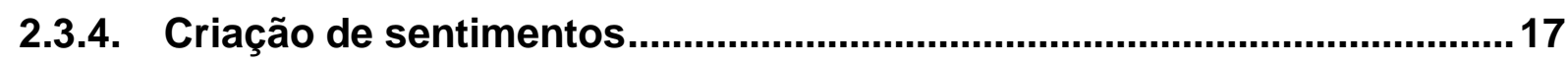

2.3.5. Reforço das relações do cliente com uma determinada comunidade...17

2.3.6. Maior nível de envolvimento dos consumidores ..................................17

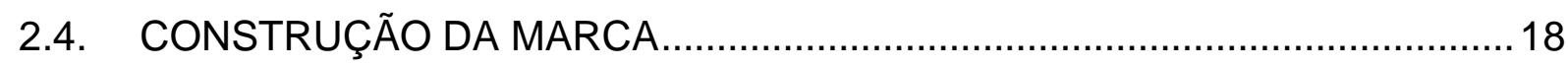

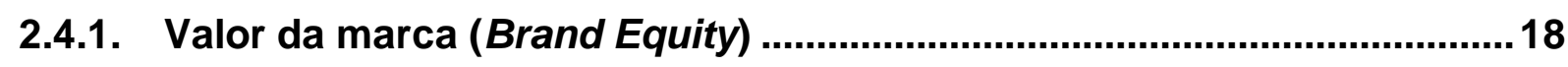

2.4.2. Experiência com a marca .....................................................................19

2.4.3. Satisfação com a marca ..................................................................19

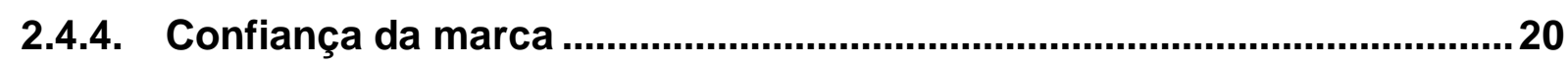

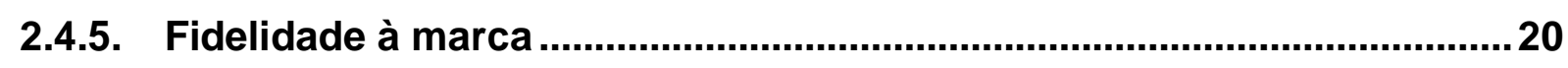

2.5. AÇÕES DE RESPONSABILIDADE SOCIAL NA DIMENSÃO INTERNA .......20

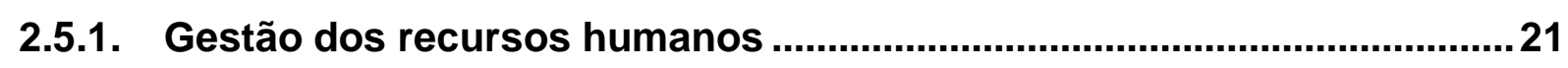

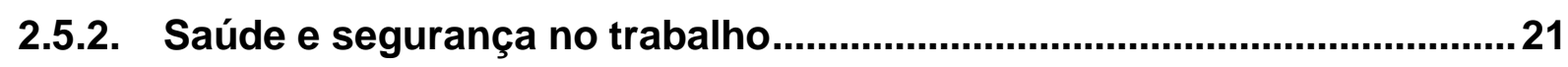

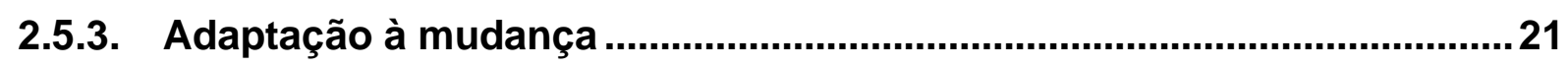

2.5.4. Gestão ambiental e dos recursos naturais ...........................................22

2.6. AÇÕES DE RESPONSABILIDADE SOCIAL NA DIMENSÃO EXTERNA ......22

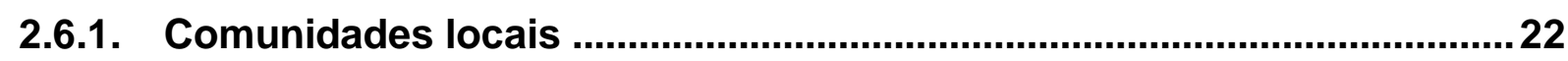

2.6.2. Parceiros comerciais, fornecedores e consumidores ..........................23

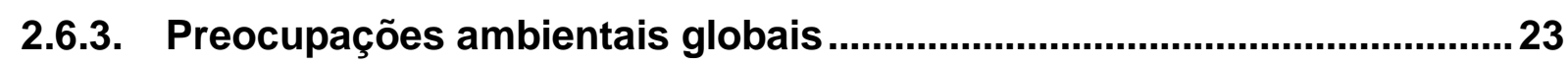

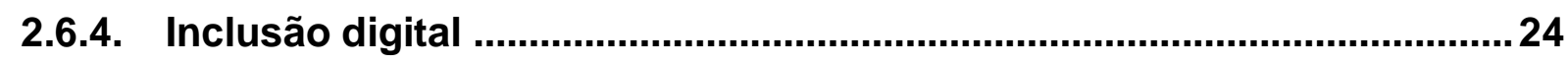

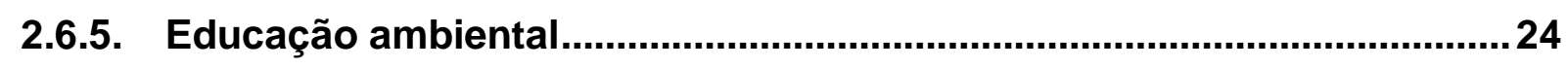

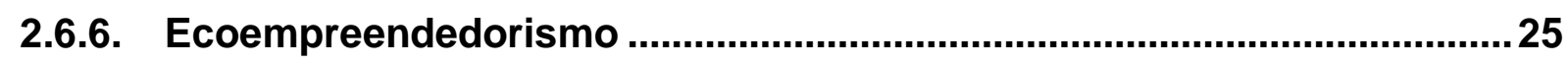

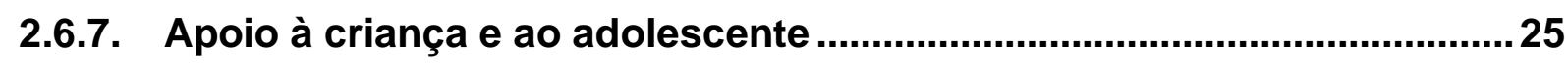

2.7. A IMPORTÂNCIA DA RESPONSABILIDADE SOCIAL NA ALAVANCAGEM

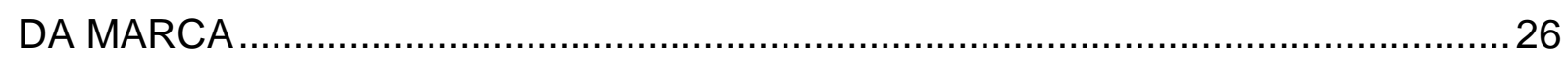

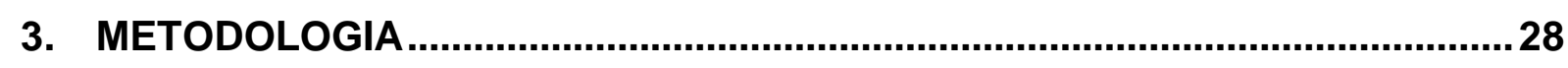




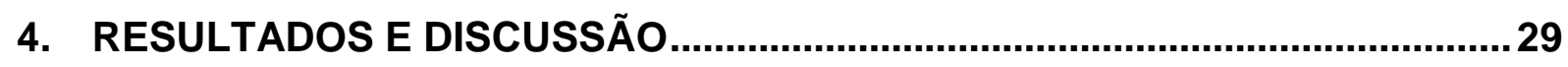

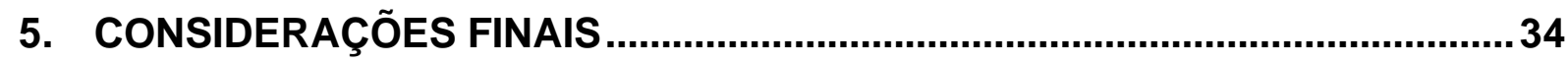

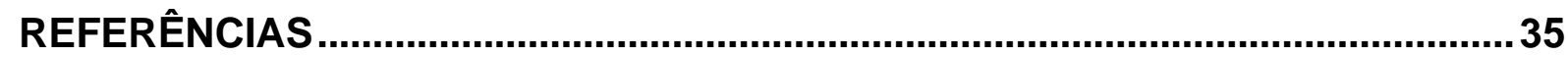




\section{INTRODUÇÃO}

No cenário atual, empresas de diversos setores têm se preocupado com questões ambientais e sociais, a nível internacional, de modo que tais organizações têm aplicado ações de responsabilidade social na sua gestão. É importante enfatizar que somente o lucro não é mais a única preocupação das empresas, uma vez que, desenvolver e aplicar ações de responsabilidade social torna-se essencial para sobrevivência das organizações.

Ser uma empresa socialmente responsável tornou-se um diferencial no mundo dos negócios, pois com o consumidor cada vez mais exigente, a busca por produtos e serviços de uma empresa socialmente responsável torna-se a preferência do consumidor.

A responsabilidade social corporativa ganhou cada vez mais interesse de gestores e acadêmicos na última década, sendo sua relevância atribuída aos seus efeitos na reputação corporativa e na mitigação de crises. Pesquisas anteriores também provaram o valor econômico direto da responsabilidade social corporativa, com o envolvimento das empresas em iniciativas socialmente responsáveis, sendo recompensadas com um impacto positivo no valor da marca. A justificativa para esse efeito é que os consumidores apreciam o comportamento altruísta das empresas, o que contribui para promover uma sensação positiva de bem-estar naqueles que os apoiam, aumenta a avaliação da marca, melhora os sentimentos da marca, além da confiabilidade (MARIN et al., 2016).

A responsabilidade social não é uma obrigação legal, mas sim um compromisso ético com as partes envolvidas ao redor da empresa. Além de haver preocupação com a questão social, há também a preocupação com o meio ambiente, assim, muitas organizações têm em sua gestão programas com objetivo de preservar o meio ambiente, o que para essas organizações é importante, visto que elas dependem de recursos naturais, principalmente para o fornecimento de sua matéria-prima.

Diante do exposto, surge a seguinte questão de pesquisa: Qual a importância da responsabilidade social para alavancar a marca das empresas? Tal questão será respondida no decorrer deste estudo.

A pesquisa tem como objetivo geral refletir respeito da responsabilidade social na alavancagem de marcas empresariais. 
E como objetivos específicos:

- Entender o que é responsabilidade social corporativa, através de conceitos de diferentes autores, além de destacar questões importantes sobre o assunto;

- Entender como a marca é construída perante o mercado;

- Identificar as ações de responsabilidade social que são aplicadas na dimensão interna e externa das empresas.

\subsection{JUSTIFICATIVA}

É cada vez mais nítida a importância que as empresas têm dado à responsabilidade social, entendendo-se ser frequente a preocupação das empresas com problemas sociais e ambientais. Esse assunto tem gerado bastante discussões entre empresários e organizações de vários setores. Empresas que agem com responsabilidade social estão à frente no mercado, de modo que tal empresa é vista como uma organização diferente em relação à concorrência.

De acordo com o SEBRAE (2017), uma empresa que pratica responsabilidade social é vista como respeitável e ética. Assim o consumidor passa a valorizar a organização que se preocupa com o ser humano e o meio ambiente, e torna-se fiel ao empreendimento. Além disso, empresas que se preocupam com a sustentabilidade contam com acessos a financiamentos mais rápidos, pois há confiança e longevidade no relacionamento com seus públicos.

Portanto, a relevância científica do projeto dá-se pelos estudos referentes à responsabilidade social e ambiental, além de servir de parâmetro para novas pesquisas, auxiliando na compreensão da importância da responsabilidade social.

A escolha do tema também prende-se ao fato de estar diretamente ligada com a área de estudo da pesquisadora, o que contribui para o enriquecimento do conhecimento e do desempenho profissional.

Além disso, este projeto possui relevância social, pois contribui para a dignidade humana, por colaborar para a comunidade local e global, através de ações e projetos sociais e ambientais. 


\section{REVISÃO BIBLIOGRÁFICA}

\subsection{DEFINIÇÃO DE RESPONSABILIDADE SOCIAL CORPORATIVA}

Atualmente, a responsabilidade social vem sendo discutida e ganhando relevância nas pautas de discussões de empresas. Visando contribuir para o bemestar social, empresas e o poder público se unem no objetivo de praticar ações de ética e responsabilidade socioambiental.

De acordo com Ribeiro (2015) responsabilidade social corporativa é um conjunto de ações benéficas a sociedade e às corporações que são formadas pelas empresas, considerando fatores como educação, saúde, moradia, meio ambiente, transporte e governo.

Segundo o Livro Verde (2001) a responsabilidade social corporativa pode ser definida como um conceito pelo qual as empresas integram as preocupações sociais e ambientais em suas operações de negócios e a sua interação com seu público interno e externo. Esse documento indica quatro justificativas para o crescimento da responsabilidade social corporativa no meio empresarial:

1. A presença crescente de preocupações sociais nas escolhas para investimento de pessoas e organizações;

2. Os novos anseios de investidores, instituições públicas e consumidores quanto a fenômenos como a globalização e transformações na indústria;

3. A conscientização ambiental do mercado consumidor;

4. Os grandes avanços tecnológicos recentes, que possibilitam trocas de informações mais rápidas e eficazes.

De acordo com Perseguini (2015), responsabilidade social é o conjunto de ideias e práticas que fazem parte da estratégia de uma organização, cujo objetivo e gerar benefícios para as partes envolvidas e interessadas na empresa e evitar prejuízos.

De acordo com o Livro Verde (2001) ser socialmente responsável não se restringe ao cumprimento de todas as obrigações legais, implica em ir além, por meio de um maior investimento em capital humano no ambiente e nas relações com outras partes interessadas e comunidades locais. A experiência adquirida com o investimento de tecnologias e práticas empresariais ambientalmente responsáveis sugere que ir além do simples cumprimento da lei pode aumentar a competitividade de uma empresa. 
Um conjunto de empresas que obtém bons resultados em termos sociais e ecológicos, indica que tais atividades podem resultar em desempenho, crescimento e capacidade de gerar lucros superiores. O impacto econômico da responsabilidade social das empresas traduz-se em efeitos diretos e indiretos. Os impactos positivos diretos podem derivar de um melhor ambiente de trabalho, levando a um maior empenho e produtividade dos trabalhadores. Já os efeitos indiretos referem-se à atenção dos consumidores e investidores, o que aumenta as oportunidades do mercado (LIVRO VERDE, 2001).

\subsection{FATORES QUE INFLUENCIAM A RESPONSABILIDADE SOCIAL}

Ribeiro (2015) cita que há quatro justificativas para destinar atenção para recursos em prol da responsabilidade social:

1. Licença para operar que toda instituição deve obter dos órgãos governamentais, comunidades e demais públicos;

2. A necessidade de observar os efeitos da atividade empresarial na comunidade e no meio ambiente;

3. Uma conduta empresarial praticante de responsabilidade social corporativa costuma contribuir para imagem da empresa, fortalecendo sua marca e aumentando suas vendas;

4. A obrigação moral da empresa de exercer um papel correto diante à sociedade. Além disso, outro fator motivacional que leva as empresas a praticar a responsabilidade social corporativa é a grande competitividade do mercado atual, pois empresas buscam nessa iniciativa uma vantagem na disputa pela preferência do consumidor, já que a preocupação socioambiental das empresas é um fator que pode influenciar na decisão de compra (KELLER, 2013).

\subsection{RESPONSABILIDADE SOCIAL CORPORATIVA COMO RECURSO PARA MELHORAR O VALOR DA MARCA}

Uma grande vantagem da responsabilidade social corporativa é o seu impacto positivo na percepção e imagem da empresa e pode criar um vínculo emocional entre os consumidores e a marca, o que pode ser visto como um importante fator de diferenciação no ambiente altamente competitivo do mercado atual. Outras vantagens incluem o fortalecimento da imagem corporativa, aumento da moral dos funcionários, 
aumento da conscientização sobre produtos e serviços e um impacto positivo na comercialização. A imagem positiva também reduz a vulnerabilidade à publicidade negativa. Em relação à marca, a responsabilidade social corporativa tem uma série de funções importantes (MEYER, 1999; KELLER, 2013).

As principais vantagens de vincular a responsabilidade social corporativa à marca incluem (HOEFFLER, KELLER, 2002; KELLER 2013):

- Formação de conhecimento da marca;

- Reforço da imagem da marca;

- Maior confiança na marca;

- Enriquecimento da imagem da marca com novos sentimentos positivos;

- Senso de pertencer à comunidade do cliente;

- Aumento do nível de envolvimento dos consumidores.

\subsubsection{Contribuição para o conhecimento da marca}

A responsabilidade social corporativa é responsável pelo reconhecimento da marca mais do que pelos procedimentos de reclamação do consumidor. Tal responsabilidade, quando baseada na natureza do produto, aumenta a taxa de reconhecimento da marca, o que pode ser considerada uma expressão positiva da influência da responsabilidade social corporativa na marca no contexto de valor da marca (Brand Equity) (PELOZA, SHANG, 2011).

\subsubsection{Reforço da imagem da marca}

Em termos de procedimentos, é mais uma etapa na criação de valor da marca. A imagem da marca confere um significado real, que se forma na mente dos clientes. As associações podem assumir várias formas. A amizade e a singularidade das associações devem ser uma característica comum em todos os casos. No caso da responsabilidade social corporativa, a imagem é universal e, portanto, universalmente aplicável a todas as extensões da marca (KELLER, 2013).

\subsubsection{Maior confiança na marca}

As atividades de responsabilidade social corporativa geram muitas avaliações e sentimentos que, por sua vez, criam as conexões entre os consumidores e as 
marcas. Não se pode esperar que os consumidores comprem os produtos em que não confiam. A credibilidade da marca pode ser vista como um elemento essencial de sua construção e desenvolvimento, e se aplica na medida em que a marca como um todo é percebida como credível, o que reflete em áreas como profissionalismo, competência, credibilidade e gosto (KELLER, 2013). O envolvimento das empresas na solução de problemas sociais afeta diretamente a atratividade da identidade corporativa (MARIN, RUIZ, 2007).

\subsubsection{Criação de sentimentos}

Os sentimentos que a marca evoca podem ser de curto prazo e focados na intensidade da experiência, ou de longo prazo, com efeitos mais permanentes no aumento do nível de respeitabilidade (PELOZA, SHANG, 2011).

Os sentimentos básicos que as marcas socialmente engajadas podem estimular nos consumidores incluem segurança, aceitação social e autoestima. No caso do envolvimento social e sua ligação com a marca, entra-se no território dos sentimentos privados, que aumentam o grau de seriedade (KELLER, 2013).

\subsubsection{Reforço das relações do cliente com uma determinada comunidade}

Kotler e Keller (2016) afirmam que uma estratégia e programas de responsabilidade corporativa adequadamente selecionados e implementados podem afetar a natureza do relacionamento entre a marca e o consumidor. A identificação com a comunidade da marca é um fenômeno social interessante. Essas relações não são definidas pelas fronteiras, mas pelo mero uso da mesma marca. Os membros dessas comunidades são caracterizados pelo conhecimento comum, tradições e um senso de responsabilidade moral. Essa responsabilidade é da marca e, portanto, a própria marca atua como seu portador (HOEFFLER, KELLER, 2002).

\subsubsection{Maior nível de envolvimento dos consumidores}

A chamada "ressonância de marca" é a forma mais elevada de conexão do cliente com a marca. Os consumidores não recebem mais passivamente as informações de marketing, notícias e mensagens, mas por meio de seu envolvimento 
ativo eles se tornam os chamados palestrantes ou evangelistas da marca (KELLER, 2013).

\subsection{CONSTRUÇÃO DA MARCA}

O processo de branding está intimamente ligado à criação da identidade da marca. A identidade da marca pode ser definida como uma característica relativamente permanente da marca, que muitas vezes identifica o que é prometido aos clientes (HE et al., 2012).

Homburg et al., (2010) afirmam que uma marca tende a ter uma identidade forte e atrativa quando sua identidade e prestígio são mais amplos do que a identidade e o prestígio das marcas concorrentes. Se quer que a marca tenha sucesso, é necessário vincular a estratégia de negócios à ideia de marca.

Além disso, também é muito importante considerar a cultura corporativa e o design ao definir a cultura e a identidade corporativa. Uma forte cultura organizacional contribui para o sucesso econômico da marca. O objetivo principal da marca é se tornar um atalho na tomada de decisão do consumidor (ADAMSON, 2011; WOODSIDE, WALSER, 2007).

No entanto, a implementação dos recursos da marca (criação da marca e escolha das ferramentas de comunicação) é muito importante no processo de branding. O valor da marca é uma parte vital da gestão da marca, ou seja, como uma marca é percebida pelos clientes. (DE CHERNATONY, 2009).

\subsubsection{Valor da marca (Brand Equity)}

O conceito de brand equity, ou seja, o valor da marca, destaca os papéis importantes da marca na percepção do consumidor. Pode-se encontrar muitas teorias que tratam da definição de brand equity. A maioria dos especialistas considera o reconhecimento da marca, a qualidade percebida, as associações de marca, a funcionalidade, a fidelidade do cliente e a imagem da marca como os mais importantes (SVĚTLÍK, VAVREČKA, 2016).

A percepção do brand equity na perspectiva do cliente é importante porque sua força reside principalmente no que os consumidores pensam, como se sentem com ele ou o que descobriram sobre ele (KELLER, 2013). Este fenômeno é geralmente 
denominado "valor implícito da marca". A percepção do consumidor sobre o valor da marca é amplamente baseada em quais componentes de percepção a marca possui e como estes são percebidos e aceitos pelos consumidores (KOTLER, KELLER, 2016).

Neste contexto, de acordo com pesquisas anteriores conduzidas por Sahin et al. (2011), pode-se concluir que marcas fortes podem ser definidas pelos seguintes componentes: experiência com a marca; satisfação com a marca; confiança da marca; e fidelidade à marca. Cada um desses componentes será discutido nos tópicos seguintes.

\subsubsection{Experiência com a marca}

A experiência com a marca é um ato importante que cria uma relação entre o consumidor e a marca (KHAN, RAHMAN, 2015). Pode-se defini-la como impressões, sentimentos, conhecimentos e respostas comportamentais às marcas. Tem a ver com a percepção do consumidor quando está em contato com a marca (NADZRI et al., 2016).

A experiência com a marca não é um conceito de relacionamento emocional, mas representa sentimentos, conhecimentos e respostas comportamentais induzidos pelos estímulos associados à marca. Posteriormente, a experiência com a marca pode resultar em laços emocionais, mas as emoções são apenas um dos resultados internos da estimulação que resulta em uma experiência. A experiência com a marca também pode ter um impacto positivo na satisfação do consumidor, confiança e lealdade à marca (HA, PERKS, 2005).

\subsubsection{Satisfação com a marca}

Os clientes encontram marcas em diferentes condições e em várias fases de suas vidas. Essas condições afetam o relacionamento do cliente com a marca durante a jornada do consumidor. Os consumidores preferem produtos que combinem com sua imagem e expressem sua personalidade. A satisfação é uma resposta afetiva positiva aos resultados da experiência anterior (BENNETT et al., 2005).

A satisfação do cliente com a marca é um prenúncio da lealdade do cliente a ela. Se as empresas desejam aumentar a satisfação com a marca, devem proporcionar ao consumidor ofertas baseadas na experiência, as quais devem ser 
pessoais, envolventes, convincentes, memoráveis e gerar uma reação intensa e positiva (IGLESIAS et al., 2011). A satisfação com a marca pode ser considerada precursora da confiança e lealdade à marca, mas pode ser difícil alcançá-la antes da confiança na marca (AGUSTIN, SINGH, 2005).

\subsubsection{Confiança da marca}

A confiança na marca é a disposição do consumidor de contar com a capacidade da marca de cumprir sua função. É prejudicial para a construção do sucesso corporativo. Em outras palavras, marcas confiáveis são aquelas que mantêm consistentemente suas promessas e valores para os consumidores. Trata-se de como um produto é desenvolvido, fabricado, vendido, reparado e anunciado (ALAN, KABADAYI, 2014).

A confiança é um fator duradouro na mente do consumidor. A confiança na marca é baseada nas crenças positivas em relação às expectativas sobre 0 desempenho da organização e dos produtos que a marca representa e tem um efeito cumulativo na lealdade. A confiança na marca é o precursor do compromisso com a marca. O compromisso com a marca é importante para construir relacionamentos fortes entre as marcas e os consumidores (SAHIN et al., 2011; ASHLEY, LEONARD, 2009).

\subsubsection{Fidelidade à marca}

A fidelidade à marca pode ser definida como uma obrigação profunda que causa uma compra repetida do mesmo produto ou serviço. A fidelidade à marca está incluída na conceituação do fenômeno da própria marca, que é usado na avaliação do desempenho da marca (SAHIN et al. 2011). Essa lealdade é um importante tipo de barreira contra os concorrentes, pois atrair e alterar a fidelidade do cliente é uma ação muito cara e difícil (NYFFENEGGER et al. 2014).

Foroudi et al., (2018) afirmam que a lealdade é alta quando os consumidores se comunicam ativamente com a marca. A fidelidade à marca apresenta muitas vantagens como desenvolvimento da força da marca, criação de oportunidade de recompra e também torna a marca menos sensível aos concorrentes.

\subsection{AÇÕES DE RESPONSABILIDADE SOCIAL NA DIMENSÃO INTERNA}




\subsubsection{Gestão dos recursos humanos}

Conforme o Livro Verde (2001) um dos maiores desafios das empresas está em atrair trabalhadores qualificados. Entre as medidas pertinentes, incluem a aprendizagem ao longo da vida, a responsabilidade dos trabalhadores, uma melhor informação dentro da empresa, um melhor equilíbrio entre vida profissional, familiar e tempo livre, uma maior diversidade de recursos humanos, a igualdade em termos de remuneração e de perspectivas de carreira para as mulheres, a participação nos lucros, a empregabilidade, a segurança no trabalho, bem como o acompanhamento ao trabalhador que não se encontra no serviço devido à incapacidade ou lesão.

\subsubsection{Saúde e segurança no trabalho}

De acordo com o Livro Verde (2001) a abordagem à saúde e segurança no trabalho faz-se sobretudo através de medidas legislativas e de aplicação. As empresas, os governos e as organizações têm intensificado a procura de formas complementares de promoção da saúde e da segurança, utilizando-as como critérios para a aquisição de produtos e serviços de outras empresas e como elemento de marketing para a promoção dos seus próprios produtos e serviços.

Assim como aumenta a preocupação com a saúde e segurança no trabalho ou com a qualidade dos produtos e serviços, também crescem as exigências em termos de quantificação, documentação e comunicação dessas qualidades no material de marketing (LIVRO VERDE, 2001, p. 9).

Conforme o Ribeiro (2015) os critérios de saúde e segurança do trabalho têm sido incluídos, em proporções variáveis, nos programas de certificação e de rotulagem existentes em produtos e equipamentos.

\subsubsection{Adaptação à mudança}

De acordo com o Perseguini (2015), reestruturar uma empresa de forma socialmente responsável significa levar em consideração e equilibrar os interesses de todas as partes interessadas que são afetadas pelas mudanças e decisões. A restruturação deverá ser minuciosamente preparada por meio da identificação de riscos mais significativos, de uma previsão de riscos diretos e indiretos.

Este processo deverá procurar salvaguardar os direitos dos trabalhadores, permitindo-lhes receber, sempre que necessário, formação profissional suplementar, modernizar os instrumentos e processos de produção, captar investimentos públicos e privados, e definir procedimentos para a informação, 
o diálogo, a cooperação e o estabelecimento de parcerias (LIVRO VERDE, 2001, p. 11).

\title{
2.5.4. Gestão ambiental e dos recursos naturais
}

Segundo o Keller (2013) uma redução na exploração de recursos, nas emissões de poluentes ou na produção de resíduos contribuem para reduzir o impacto ambiental. Poderá ser vantajoso para as empresas, na medida que possibilita uma redução das despesas energéticas e de eliminação de resíduos, bem como nos custos de matéria-prima e despoluição. Determinadas empresas que exploram menos o meio ambiente podem ter aumento nos lucros e na competitividade.

No domínio ambiental, investimentos dessa natureza são vantajosos tanto para as empresas como para o meio ambiente. De acordo com o Livro Verde (2001), as autoridades públicas devem trabalhar em conjunto com as empresas, e um bom exemplo de abordagem que permite essas entidades trabalharem em conjunto é a política de produtos integrada, a qual assenta na ponderação do impacto de produtos ao longo do seu ciclo de vida e envolve empresas, e outras partes interessadas, num debate com vista a encontrar uma linha de ação mais rendível.

\subsection{AÇÕES DE RESPONSABILIDADE SOCIAL NA DIMENSÃO EXTERNA}

\subsubsection{Comunidades locais}

De acordo com Perseguini (2015), a responsabilidade social de uma empresa ultrapassa a esfera da própria empresa e estende-se a comunidade local, envolvendo várias partes interessadas, como: parceiros comerciais, fornecedores, clientes, autoridades públicas e ONGs que exercem a sua atividade junto a comunidades locais ou no domínio do ambiente.

\begin{abstract}
A responsabilidade social das empresas traduz-se também numa integração adequada da empresa na respectiva envolvente local a nível internacional. As empresas dão um contributo para a vida das comunidades locais em termos de emprego, remunerações, benefícios e impostos (LIVRO VERDE, 2001, p. 12).
\end{abstract}

Conforme Ribeiro (2015) a reputação de uma empresa na sua zona de implantação, enquanto agente no plano local, é um fator que influencia a competitividade. As empresas interagem com o meio físico local, algumas apostam em um ambiente limpo para produção ou prestação de serviços como ar, água limpos ou redes rodoviárias descongestionadas. Também é possível imputar às empresas a 
responsabilidade por conjunto de atividades poluentes como ruído, luz, poluição das águas, emissões aéreas, contaminação do solo e problemas ambientais inerentes ao transporte e eliminação de resíduos.

Muitas empresas empenham-se em comunidades locais, oferecem apoio de ações de promoção ambiental, recrutam pessoas vítimas de exclusão social, disponibilizam estruturas para cuidados com os filhos dos trabalhadores, parcerias com comunidades, patrocinam eventos culturais e desportivos ou donativos para ações de caridade (LIVRO VERDE, 2001).

\subsubsection{Parceiros comerciais, fornecedores e consumidores}

De acordo com o Peloza e Shang (2011) as grandes empresas têm relações comerciais com empresas de menores dimensões, seja como clientes, fornecedores, concorrentes e estão cientes de que o seu desempenho social pode ser afetado pelas práticas dos seus parceiros ou fornecedores ao longo da cadeia de produção. Os efeitos da responsabilidade social afetam também os seus parceiros econômicos.

Como parte da sua responsabilidade social, as sociedades devem procurar fornecer, de forma ética, eficiente e ecológica, produtos e serviços que os consumidores desejam e dos quais necessitam. Das empresas, que constroem relações duradouras com os clientes e que, para isso, centram toda sua organização em compreender as expectativas e necessidades dos clientes e em corresponder-Ihes com superiores, qualidade, segurança, confiabilidade e serviço, é legítimo esperar que obtenham lucros mais elevados (LIVRO VERDE, 2001, p. 14).

Investir em capitais de risco significa que a empresa maior adquire participações minoritárias numa empresa promissora em fase de arranque ou promove o seu desenvolvimento. Ambos obtêm vantagens, como uma melhor percepção de desenvolvimentos inovadores para a empresa maior, e um acesso facilitado a recursos financeiros e ao mercado para a empresa menor (KELLER, 2013).

\subsubsection{Preocupações ambientais globais}

Devido a muitos problemas ambientais relacionados com a sua atividade e a exploração de recursos mundiais, as empresas são agentes no meio global. Dessa forma, diversas empresas propõem objetivos de responsabilidade social a nível internacional. $\mathrm{O}$ investimento e as atividades das empresas em outros países são passíveis de produzir efeitos diretos no desenvolvimento econômico e social desses 
países. No cenário mundial, a relevância do papel das empresas no desenvolvimento sustentável é cada vez mais acentuada (LIVRO VERDE, 2001; RIBEIRO, 2015).

\subsubsection{Inclusão digital}

De acordo com Stadler et al. (2014) fundado em 1926, o Laboratório Fleury oferece soluções na área da saúde, realiza em média 6 milhões de exames anualmente, tem em seu quadro mais de dois mil funcionários e 300 médicos, que atendem cerca de 18 unidades localizadas em São Paulo, Rio de Janeiro e Brasília. Foi implantado em 2001 o Projeto Gestação, cujo objetivo era acompanhar a gestação das mulheres grávidas da cidade de Jabaquara. Além do atendimento clínico, o laboratório diagnosticava e implantava programas educacionais.

Além disso, o laboratório implantou o projeto de capacitação cujo objetivo era ensinar informática para os moradores da cidade de Jabaquara, um projeto de inclusão digital que era realizado nas dependências do centro de educação do Laboratório Fleury.

Com o envolvimento dos funcionários do laboratório, envolvimento do poder público, parcerias estratégicas, e com o apoio de organizações não governamentais (ONGS) o projeto obteve bons resultados, o monitoramento é imprescindível para se avaliar e corrigir o andamento do projeto, mas para formar uma comunicação consistente para o mercado (STADLER et al., 2014).

\subsubsection{Educação ambiental}

Segundo Stadler et al. (2014), a empresa Canavieiras Transportes LTDA, fundada em 1927, atua a mais de 80 anos na área de transportes coletivos urbanos na cidade de Florianópolis, Santa Catarina. Conta com aproximadamente 140 veículos que fazem itinerários por todo o norte da cidade e 650 funcionários.

A empresa implantou um projeto de educação ambiental, com o objetivo de oferecer aos colaboradores orientações sobre a correta separação do lixo, além de propor palestras de educação ambiental. Com objetivo de tornar possível essas ações, a organização reforçou sua comunicação interna e externa em seu site e em jornais informativos (STADLER et al., 2014).

Os resultados obtidos foram os melhores, como reforço de sua imagem interna e externa, comprometimento dos colaboradores, reforço com a conscientização 
ambiental com a participação da comunidade e funcionários, além da quantidade de material doado para instituições beneficiadas (STADLER et al., 2014).

\title{
2.6.6. Ecoempreendedorismo
}

De acordo com Miranda (2006 apud STADLER et al., 2014) a definição de ecoempreendedorismo é inovar e transformar, atendendo aos princípios básicos do socialmente justo, ambientalmente correto e viável para a economia.

\begin{abstract}
Tanto a reutilização quanto a inovação, conforme os princípios do ecoempreendedorismo, devem atender os princípios básicos daquilo que é justo para as pessoas, correto em termos ambientais e possível de ser implantado em termos econômicos. Nesse sentido, vê-se aqui claramente o conceito de sustentabilidade, ou seja, o resultado do equilíbrio entre as dimensões econômica, social e ambiental (STADLER et al., 2014, p. 155).
\end{abstract}

Um exemplo de ecoempreendedorismo é um microfone ecológico criado por um empreendedor, que utiliza resíduos de madeira da Amazônia para fabricar esse produto com qualidade aprovada pelo Instituto Nacional de Pesquisa da Amazônia (IMPA). A implantação de projetos de responsabilidade social não depende do porte da empresa e sim do comprometimento da alta direção, planejamento e monitoramento (STADLER et al., 2014).

A formação de parcerias estratégicas é fundamental para o sucesso do projeto. O Ecoempreendedorismo é um conceito relacionado ao reaproveitamento de materiais, mas, inclusive, ao pensamento social e ambiental.

\subsubsection{Apoio à criança e ao adolescente}

De acordo com Munhoz (2015) na Lei 8.069, de 13 de julho de 1990, que estabeleceu a garantia dos direitos da criança e do adolescente no Brasil, ficou assegurado que elas possuem os mesmos direitos que os adultos e seriam asseguradas por Lei todas as oportunidades para seu desenvolvimento físico, mental, moral, espiritual e social e em condições de liberdade e dignidade. Ao estado, a sociedade e à família cabem a responsabilidade pelo cumprimento da lei sendo obrigados a assegurar os direitos das crianças e adolescentes à vida, à saúde, à alimentação, à educação, ao esporte, ao lazer, à profissionalização, à cultura, à dignidade, ao respeito e ao convívio familiar e comunitário. 
Apesar de existir uma Lei que protege esse segmento social, é evidente que não resolveu o problema desse setor, sendo assim, organizações não governamentais passaram a elencarem o bem-estar da criança e adolescente como objetivo, além da atenção da empresa moderna como parte integrante de um processo de efetivação de comportamento ético e de responsabilidade e autoridade social (MUNHOZ, 2015).

Segundo Stadler et al. (2014) as organizações do terceiro setor apontam como problemas ainda vigentes e em escala crescente o aumento da mortalidade infantil, aumento da desnutrição infantil, o aumento de crianças na miséria, o aumento de crianças sem escolaridade e baixa qualidade de vida.

\title{
2.7. A IMPORTÂNCIA DA RESPONSABILIDADE SOCIAL NA ALAVANCAGEM DA MARCA
}

De acordo com Pontes et al. (2014) em busca de fortalecer sua marca e beneficiar seu público interno e externo, organizações de diferentes setores, adotam ações de responsabilidade social que tem feito sucesso graças ao comprometimento e envolvimento do seu público em geral.

\begin{abstract}
A preocupação dos empresários, quando o assunto é implantar a responsabilidade social, é a viabilidade relacionada a custos para a implantação de práticas sociais, já que para a realização das mesmas terão que ser mobilizados recursos financeiros. No entanto, cabe ressaltar os benefícios gerados por essas práticas que podem ultrapassar as expectativas, propiciando não só o aumento de competitividade como também agregar valor à sua marca (DIAS 2012, p. 26, apud PONTES et al., 2014).
\end{abstract}

De acordo com Mello Neto e Fróes (1999 apud PONTES et al., 2014) com a imagem reforçada e dependendo dos resultados dos projetos sociais por ela financiados, a empresa torna-se mais conhecida e vende mais. Seus produtos, serviços e sua marca ganham maior visibilidade, aceitação e potencialidade. Clientes tornam-se orgulhosos de adquirir produtos e serviços de uma marca com elevada responsabilidade social.

Para Argenti (2014) embora a responsabilidade social empresarial esteja assumindo um papel central graças a um ambiente de negócios que enfrenta riscos cada vez maiores, adotar uma estratégia socialmente responsável pode oferecer uma vantagem atraente para grandes empresas. Práticas responsáveis de negócios não minam necessariamente os lucros de uma empresa. 
Segundo Santana e Oliveira (2016) a estratégia utilizada por uma organização referente à responsabilidade social pode trazer inúmeros benefícios, entre eles, fidelidade do cliente, gerenciamento de riscos no tocante à reputação organizacional, interesse dos colaboradores mais qualificados e redução de custos operacionais.

Pesquisas mostram que seu efeito vem aumentando, e mais da metade dos
executivos acredita que um compromisso declarado para com a
responsabilidade social corporativa contribui em muito para a reputação geral
da empresa. Estudos recentes também revelam que, para decidir em que
empresas confiar, universitários americanos estão começando a considerar
a responsabilidade social como fator mais importante do que marca
corporativa ou desempenho financeiro, seguido da qualidade de produtos e
serviços (ARGENTI, 2014, p. 148-149).

Dias (2012 apud PONTES et al., 2014) afirma que a adoção de práticas sociais das empresas está cada vez mais sendo valorizada por entidades governamentais, nas esferas municipal, estadual e federal, muitas dessas ações praticadas por empresas são frutos da ineficiência de políticas públicas do país.

\begin{abstract}
Além de agregar valor à marca, uma empresa socialmente responsável consegue maior competitividade retendo e recrutando colaboradores qualificados que possam usar suas habilidades no desempenho de operações mais eficientes para empresa. A organização que investe em todos os vetores que orientam a responsabilidade social (RS) consegue uma relação mais eficaz com um dos seus principais stakeholders, o capital humano, ou seja, a ferramenta mais importante de que dispõe as empresas atualmente. Diariamente bons profissionais buscam um emprego que supram seus principais anseios; os quais vão muito além de uma boa remuneração ou uma oportunidade de galgar bons cargos na instituição (PONTES et al., 2014, p. 8).
\end{abstract}

De acordo Pontes et al. (2014) as empresas socialmente responsáveis buscam fornecedores com as mesmas características, pois os mesmos agregam valor a sua cadeia de suprimentos. As organizações que não estão alinhadas com fornecedores que possuem as mesmas práticas, podem ter sua imagem e sua rentabilidade comprometidas por algum comportamento inadequado que os fornecedores venham a cometer. Exigir de seus fornecedores a adoção de práticas de responsabilidade social e monitorar o seu cumprimento é importante para evitar futuros transtornos ou prejuízos, e demonstra que a empresa está empenhada na criação de um vínculo com parceiros de qualidade que se preocupam com o bem-estar social. 


\section{METODOLOGIA}

O instrumento utilizado na pesquisa é bibliográfico. Conforme Gil (2008) a pesquisa bibliográfica é desenvolvida a partir do material já elaborado, constituído por livros e artigos científicos. Parte dos estudos exploratórios podem ser definidos como pesquisas bibliográficas, assim como certos números de pesquisas envolvidas a partir da técnica da análise de conteúdo.

Para coleta de dados foram utilizados artigos, livros e revistas de natureza cientifica, por meio das seguintes bases de dados: Google Scholar, SciELO e Scopus. Os critérios de inclusão utilizados na triagem dos artigos foram: estudos realizados a partir do ano de 2005; estudos publicados nos idiomas português e inglês; estudos aderentes ao tema; e estudos com disponibilidade de texto completo. Para a indexação nas bases de dados, foram utilizados os seguintes termos: responsabilidade social corporativa, alavancagem de marca e valor da marca.

Foi aplicada na pesquisa uma análise de conteúdo afim de interpretar as informações. De acordo com Bardin (2011), análise de conteúdo foca na mensagem que os autores transmitem, o objetivo é a manipulação de mensagens para confirmar os indicadores. Foram analisadas e comparadas as ideias dos autores apresentados na tabela abaixo.

Tabela 1: Estudos utilizados na discussão

\begin{tabular}{|c|c|c|}
\hline AUTOR & TíTULO DO ESTUDO & ANO \\
\hline Bigné et al. & $\begin{array}{c}\text { Dual nature of cause-brand fit: Influence on corporate } \\
\text { social responsibility consumer perception }\end{array}$ & 2012 \\
\hline Barone et al. & $\begin{array}{c}\text { Resposta do consumidor ao uso do varejo de marketing } \\
\text { relacionado a causas: mais ajuste é melhor? }\end{array}$ & 2007 \\
\hline $\begin{array}{c}\text { Chernev e } \\
\text { Blair }\end{array}$ & $\begin{array}{c}\text { Doing well by doing good: The benevolent halo of } \\
\text { corporate social responsibility }\end{array}$ & 2015 \\
\hline $\begin{array}{c}\text { Hoeffler e } \\
\text { Keller }\end{array}$ & $\begin{array}{c}\text { Construindo o patrimônio da marca por meio do } \\
\text { marketing social }\end{array}$ & 2002 \\
\hline $\begin{array}{c}\text { Hoek e } \\
\text { Gendall }\end{array}$ & $\begin{array}{c}\text { Uma análise das respostas dos consumidores ao } \\
\text { marketing relacionado à causa }\end{array}$ & 2008 \\
\hline $\begin{array}{c}\text { Lafferty e } \\
\text { Goldsmith }\end{array}$ & $\begin{array}{c}\text { Cause-brand alliances: does the cause help the brand } \\
\text { or does the brand help the cause? }\end{array}$ & 2005 \\
\hline Marin et al. & $\begin{array}{c}\text { Determinantes das atribuições de responsabilidade } \\
\text { social corporativa do consumidor. }\end{array}$ & 2016 \\
\hline Montoro et al. & $\begin{array}{c}\text { Melhorando as atitudes em relação às marcas com } \\
\text { associações ambientais: uma abordagem experimental }\end{array}$ & 2006 \\
\hline Nan e Heo & $\begin{array}{c}\text { Respostas do consumidor às iniciativas de } \\
\text { responsabilidade social corporativa (CSR): Examinando } \\
\text { o papel do ajuste de causa da marca no marketing } \\
\text { relacionado a causas }\end{array}$ & 2007 \\
\hline
\end{tabular}

Fonte: Autor 


\section{RESULTADOS E DISCUSSÃO}

Vários autores realizaram diversos tipos de estudos para determinar qual o real impacto que a responsabilidade social corporativa possui na alavancagem das marcas empresariais. Sendo assim, Hoeffler e Keller (2002) demonstraram que o efeito da responsabilidade social corporativa nos consumidores ocorre por meio de seu impacto em várias dimensões do conhecimento da marca, entre elas: imagem, consciência, credibilidade, sentimentos, envolvimento e comunidade da marca.

As associações de responsabilidade social corporativa agregam as percepções dos consumidores sobre a natureza social de uma marca. Na maioria dos estudos, as associações de responsabilidade social corporativa são tratadas como uma construção simples para capturar as percepções sociais gerais da marca.

No entanto, Montoro et al. (2006) apresentam as associações de responsabilidade social corporativa como um construto composto por três tipos de associações: funcional, experiencial e social. O primeiro reúne as associações de responsabilidade social corporativa que os consumidores relacionam diretamente ao desempenho do produto ou serviço. $O$ segundo tipo envolve os sentimentos e emoções que os consumidores experimentam ao apoiar iniciativas de responsabilidade social corporativa. O terceiro tipo envolve as associações relacionadas ao valor de identidade social que os consumidores encontram ao ajudar as causas sociais.

Além disso, as atribuições dos consumidores são frequentemente avaliadas por seus efeitos sobre a atitude da marca, intenções de compra e associações de responsabilidade social corporativa (BIGNÉ et al., 2012; CHERNEV, BLAIR, 2015). Esses efeitos ocorrem quando os consumidores aceitam que as empresas são movidas por seus valores genuínos e encontram uma adequação lógica para o acordo entre a marca e a causa (voltado para a estratégia). Em contraste, os efeitos tendem a ser negativos quando os consumidores atribuem as motivações das empresas para apoiar iniciativas de responsabilidade social corporativa a razões egoístas ou lucrativas (MARIN et al., 2016). A adesão à causa da marca está entre os fatores que mais influenciam as atribuições dos consumidores (MONTORO et al., 2006; BIGNÉ et al., 2012; MARIN et al., 2016). 
A adesão à causa da marca tem sido um tópico proeminente em estudos anteriores que avaliaram os efeitos da responsabilidade social corporativa no valor da marca (CHERNEV, BLAIR, 2015; NAN, HEO, 2007). Esse destaque pode ser atribuído a dois aspectos. Primeiro, porque a adesão à causa da marca tem uma influência importante nos efeitos do marketing relacionado à causa no valor da marca (HOEFFLER, KELLER, 2002). E em segundo lugar, porque o marketing relacionado a causas é o tipo mais pesquisado de responsabilidade social corporativa.

Apesar do entendimento de que a alta adesão do público à causa da marca é o contexto mais desejado pelas empresas, alguns estudos demonstram também que, dependendo do produto e da empresa, casos de baixa adesão do público à causa da marca podem ser irrelevantes (MARIN et al., 2016; CHERNEV, BLAIR, 2015). Com base em Nan e Heo (2007), os efeitos das iniciativas de responsabilidade social corporativa na atitude da marca revelam que a alta adesão à causa da marca podem influenciar apenas nos resultados para consumidores altamente conscientes da marca. Chernev e Blair (2015) avaliam os efeitos da responsabilidade social corporativa no desempenho do produto em contextos de baixa adesão à causa da marca. As descobertas indicam que os efeitos no desempenho do produto são mais fortes quando atribuições são percebidas ou os consumidores têm menos conhecimento sobre o produto.

Outros estudos investigaram as condições sob as quais os efeitos da alta adesão à causa da marca são significativos. Os resultados indicam que a alta adesão à causa da marca tem um efeito positivo nas intenções dos consumidores apenas quando as atribuições são positivas, mas não agrega valor quando as atribuições dos consumidores são negativas. Além disso, se a causa da marca é familiar ao público, então a alta adesão do público à causa da marca é menos importante (BARONE et al., 2007).

Em relação aos argumentos teóricos de apoio, estudos anteriores propuseram que os efeitos da responsabilidade social corporativa sobre o valor da marca ocorrem por meio de mecanismos relacionados à transferência de imagem e atribuições dos consumidores.

Para explorar os mecanismos de transferência de imagem, é importante definir como a adesão à causa da marca se relaciona com o conhecimento da marca. Keller (2013) afirma que o conhecimento da marca é aceito como a principal fonte de valor 
da marca, sendo composto pelo reconhecimento da marca e vários tipos de associações de marca. As associações de marca podem ser criadas diretamente por meio da comunicação da marca, inovação e experiência do produto ou podem ser transferidas de fontes secundárias por meio de mecanismos de transferência de imagem.

Keller (2013) introduz o conceito de associações secundárias de marca para definir esse processo, referindo-se à transferência de imagem que ocorre entre as partes como resultado de seus esforços conjuntos de marketing. As associações secundárias no contexto da responsabilidade social corporativa podem ocorrer entre a causa e a marca, com os consumidores aprendendo sobre a marca ao associá-la à causa.

Esse mecanismo encontra suporte na teoria do condicionamento clássico, segundo o qual o ser humano pode aprender sobre um estímulo (por exemplo, uma marca) associando-o a outro objeto (TILL, NOWAK, 2000). No contexto específico da responsabilidade social corporativa, a lógica é que quando as empresas são apoiadas pelas causas que apoiam, ocorre a transferência de associações da causa para a marca e, como resultado, os consumidores podem ver a marca como mais socialmente responsável (HOEFFLER, KELLER, 2002; BARONE et al., 2007). Diante dessa lógica, os pesquisadores propõem que a percepção dos consumidores sobre a adesão entre a marca e os estímulos está entre as condições mais importantes para que o mecanismo de transferência de imagem ocorra devido à nova imagem da marca perante o mercado (BIGNÉ et al., 2012).

Nesse sentido, dois conceitos devem ser entendidos: o diagnóstico e a acessibilidade. O conceito de diagnóstico implica que em situações nas quais os consumidores percebem uma alta similaridade e compatibilidade de associações entre uma marca e a causa, eles perceberão que podem fazer julgamentos sobre a marca com base no que sabem sobre a causa. Portanto, a informação sobre a causa serve como base para os julgamentos dos consumidores sobre a marca. Já o conceito de acessibilidade implica que, quando os consumidores percebem alta adequação entre a causa e a marca, as associações transferidas tendem a reforçar associações de marca pré-existentes e torná-las mais acessíveis na memória, com um impacto positivo nas avaliações da marca (KELLER, 2013; BIGNÉ et al., 2012).

Estudos anteriores de responsabilidade social corporativa concluíram que, em contextos nos quais a adesão à causa da marca é alta, o diagnóstico e a 
acessibilidade têm um efeito positivo nas avaliações da marca, associações de responsabilidade social corporativa e respostas dos consumidores (CHEN et al., 2014; LAFFERTY, GOLDSMITH, 2005).

No entanto, ao mesmo tempo que se beneficiam dos mecanismos de transferência de imagem, além de seguir uma estratégia de comunalidade, as marcas também podem considerar estratégias de complementaridade, que implicam na adequação entre a marca e a causa moderada ou baixa (HOEFFLER, KELLER, 2002). Nesse tipo de estratégia, o objetivo é que as marcas construam novos pontos de diferenciação por meio da criação de novas associações (CHEN et al., 2014; BIGNÉ et al., 2012; KELLER, 2013).

$\mathrm{Na}$ perspectiva de Chen et al. (2014), a imagem de responsabilidade social corporativa pré-existente das marcas deve ser considerada ao decidir por comunalidade versus complementaridade. Os autores recomendam que as marcas que já são conhecidas por associações positivas de responsabilidade social corporativa devem buscar uma maior adesão à causa da marca, pois isso ajuda a reforçar as associações existentes. No entanto, marcas conhecidas por sua capacidade corporativa na produção e comercialização de bens e serviços, mas sem associações de responsabilidade social corporativa, se beneficiariam mais de uma adesão à causa moderada ou baixa, o que permitiria a diferenciação. Em ambas as situações, é desejável algum tipo de familiaridade do consumidor com a causa para que as associações sejam transferidas.

Além de mecanismos relacionados à transferência de imagem, estudos anteriores também propuseram que os efeitos da responsabilidade social corporativa no valor da marca ocorrem por meio das características dos consumidores em relação às motivações das empresas para apoiar as iniciativas de responsabilidade social corporativa (MARIN et al., 2016; BARONE et al., 2007). O raciocínio por trás desses efeitos é que quando a adesão da marca está alta, os consumidores podem facilmente conseguir motivos para aderir. Nessas situações, os consumidores tendem a aceitar que as motivações das empresas são movidas por aspectos mais positivos, relacionados à sua estratégia e valores (BIGNÉ et al., 2012). Por outro lado, quando os consumidores percebem uma baixa adesão, eles acham difícil entender as associações da causa com a marca. Nessas situações ocorre dissonância cognitiva, em resposta à qual os consumidores tendem a elaborar pensamentos mais suspeitos sobre os motivos que justificam o acordo marca-causa. Em suma, quando os 
consumidores não conseguem entender as motivações da empresa para estabelecer - acordo entre causa e marca, tendem a atribuir negativamente a empresa, associando-a a motivos egoístas (MARIN et al., 2016; BIGNÉ, 2012).

Nessa perspectiva, pressupõe-se que, ao se deparar com um acordo entre causa e marca, os consumidores fazem um esforço para entender sobre as motivações das empresas. Esse poderia ser o caso da escolha de uma seguradora ou software, que são tipos de produtos de alto envolvimento (HOEK, GENDALL, 2008). No entanto, ao escolher cerveja, água ou comida, um nível mais baixo de envolvimento com o produto é esperado, de modo que os consumidores naturalmente façam menos julgamentos ao longo do processo de tomada de decisão (LAFFERTY, GOLDSMITH, 2005; HOEK, GENDALL, 2008).

Seguindo esse raciocínio, alguns autores propõem que em contextos de baixo envolvimento com o produto, os consumidores não refletem tanto sobre as motivações das empresas para apoiar a causa e, portanto, os riscos de atribuições negativas do consumidor associadas com baixa adequação entre causa e marca tornam-se menos relevantes (LAFFERTY, GOLDSMITH, 2005; HOEK, GENDALL, 2008). 


\section{CONSIDERAÇÕES FINAIS}

O objetivo geral deste estudo foi refletir sobre a responsabilidade social corporativa na alavancagem de marcas de empresas. O estudo abordou conceitos de responsabilidade social corporativa, demonstrou como é a construção de uma marca no mercado, apresentou ações de responsabilidade social nos contextos internos e externos às empresas. A pesquisa bibliográfica foi o método que permitiu que o estudo fosse concluído de maneira clara e sucinta.

Respondendo à questão abordada no início do estudo, entende-se que a responsabilidade social corporativa possui uma grande importância para a alavancagem das marcas empresariais, de modo que, este é considerado um método passível de destaque no mercado, pois a empresa que o utiliza tende a obter maiores retornos financeiros e maior destaque de sua marca no mercado por meio de seus atos de responsabilidade social.

Além disso, por meio da discussão, foi possível entender que tal método deve ser utilizado com responsabilidade, de modo que a empresa realmente foque no auxílio à sociedade e não somente nos lucros, pois, a partir do momento que o cliente percebe que a empresa não está focada na causa, e sim somente na obtenção de lucros, os clientes podem se virar contra a empresa, fazendo-a perder espaço no mercado. 


\section{REFERÊNCIAS}

ADAMSON, A. P. Simplesmente marca: como as melhores marcas se basearam na simplicidade e tiveram sucesso. Bratislava: Eastone Books. 2011.

AGUSTIN, C.; SINGH, J. Curvilinear effects of consumer loyalty determinants in relational exchanges. Journal of marketing research, 42(1), 96-108. 2005.

ALAN, A. K.; KABADAYI, E. T. Quality antecedents of brand trust and behavioral intention. Procedia-Social and Behavioral Sciences, 150, 619-627. 2014.

ARGENTI, P. A comunicação empresarial: a construção da identidade, imagem e reputação. 6. ed. São Paulo: Campus, 2014.

ASHLEY, C.; LEONARD, H. A. Betrayed by the buzz? Covert content and consumerbrand relationships. Journal of Public Policy \& Marketing, 28(2), 212-220. 2009.

BARDIN, Laurence. Análise de conteúdo. São Paulo: Edições 70, 2011, p. 229.

BARONE, M. J.; NORMAN, A. T.; MIYAZAKI, A. D. Resposta do consumidor ao uso do varejo de marketing relacionado a causas: mais ajuste é melhor? Journal of Retailing, 83(4), 437-445. 2007.

BENNETT, R.; RUNDEL-THIELE, S. O ciclo de vida da fidelidade à marca: implicações para os profissionais de marketing. Journal of Brand Management, 12(4), 250-263. 2005. 
BIGNÉ, E.; CURRÁS-PÉREZ, R.; ALDÁS-MANZANO, J. Dual nature of cause-brand fit: Influence on corporate social responsibility consumer perception. European Journal of Marketing, 46(3/4), 575-594. 2012.

CHERNEV, A.; BLAIR, S. Doing well by doing good: The benevolent halo of corporate social responsibility. Journal of Consumer Research, 41(6), 1412-1425. 2015.

DE CHERNATONY, L. Marca: da visão aos lucros maiores. Brno: Computer press, a.s. 2009.

FOROUDI, P., et al. Perceptional components of brand equity: Configuring the Symmetrical and Asymmetrical Paths to brand loyalty and brand purchase intention. Journal of Business Research, 89, 462-474. 2018.

GIL, Antônio Carlos. Como elaborar projetos de pesquisa. São Paulo: Atlas, 2008.

HA, H.Y.; PERKS, H. Effects of consumer perceptions of brand experience on the web: brand familiarity, satisfaction and brand trust. Journal of Consumer Behaviour, 4, 438- 452. 2005.

HE, H.; LI, Y.; HARRIS, L. Social identity perspective on brand loyalty. Journal of Business Research, 65(5), 648-657. 2012.

HOEFFLER, S.; KELLER, K. L. Construindo o patrimônio da marca por meio do marketing social. Journal of Public Policy \& Marketing, 21(1), 78-89. 2002.

HOEK, J.; GENDALL, P. An analysis of consumers' responses to cause related marketing. Journal of Nonprofit \& Public Sector Marketing, 20(2), 283-297. 2008.

HOMBURG, C.; KLARMANN, M.; SCHIMITT, J. Brand awareness in business markets: When is it related to firm performance? International Journal of Research in Marketing, 27(3), 201-212. 2010. 
IGLESIAS, O., et al. O papel da experiência da marca e do compromisso afetivo na determinação da fidelidade à marca. Journal of Brand Management, 18(8), 570-582. 2011.

KELLER, K. L. Strategic Brand Management: Building, Measuring, and Managing Brand Equity (Global edition). Harlow, GB: Pearson Education Limited. 2013.

KHAN, I.; RAHMAN, Z. Mecanismo de formação de experiência de marca e seus possíveis resultados: um referencial teórico. The Marketing Review, 15(2), 239-259. 2015.

KOTLER, P.; KELLER, K. L. Marketing Management (15th Edition). Harlow: Pearson Education Limited. 2016.

LAFFERTY, B. A.; GOLDSMITH, R. E. Cause-brand alliances: does the cause help the brand or does the brand help the cause?. Journal of business research, 58(4), 423-429. 2005.

LIVRO, Verde. Promover um quadro europeu para a responsabilidade social das empresas. Bruxelas. Comissão das comunidades europeias. 2001.

MARIN, L.; CUESTAS, P. J.; ROMÁN, S. Determinantes das atribuições de responsabilidade social corporativa do consumidor. Journal of Business Ethics, 138(2), 247-260. 2016.

MARIN, L.; RUIZ, S. "I need you too!" Corporate identity attractiveness for consumers and the role of social responsibility. Journal of Business Ethics, 71(3), 245-260. 2007.

MEYER, H. Quando a causa é justa. Journal of Business Strategy, 20(6), 27-31. 1999.

MONTORO Rios, F. J.; LUQUE Martinez, T.; FUENTES Moreno, F.; CAÑADAS Soriano, P. Melhorando as atitudes em relação às marcas com associações 
ambientais: uma abordagem experimental. Journal of Consumer Marketing, 23(1), 26-33. 2006.

MUNHOZ, Antonio Siemsen. Responsabilidade e autoridade social das empresas. Curitiba: Edição 1. Editora Intersaberes. 2015.

NADZRI, W. N. M. et al. Os antecedentes da experiência da marca na indústria automotiva nacional. Procedia Economics and Finance, 37, 317-323. 2016.

NAN, X.; HEO, K. Respostas do consumidor às iniciativas de responsabilidade social corporativa: Examinando o papel do ajuste de causa da marca no marketing relacionado a causas. Journal of advertising, 36(2), 63-74. 2007.

NYFFENEGGER, B., et al. Service brand relationship quality: hot or cold? Journal of Service Research, 18(1), 90-106. 2015.

PELOZA, J.; SHANG, J. How can corporate social responsibility activities create value for stakeholders? A systematic review. Journal of the Academy of Marketing Science, 39(1), 117-135. 2011.

PERSEGUINI, Alayde dos Santos. Responsabilidade Social. São Paulo. Editora Pearson. 2015.

PONTES, Ronaldo Miranda et al. A influência da responsabilidade social na geração de valor: Estudo de caso na Medquímica. XI Simpósio de Excelência em Gestão e Tecnologia. Aedb. 2014. Disponível em: < https://www.aedb.br/seget/arquivo s/artigos14/27220305.pdf> Acesso em: 21 de maio de 2020.

RIBEIRO, Lucyara. Marketing social e comportamento do consumidor. São Paulo. Editora Pearson. 2015.

SAHIN, A., et al. Os efeitos das experiências de marca, confiança e satisfação na construção da fidelidade à marca; uma pesquisa empírica sobre marcas globais. Procedia-Social and Behavioral Sciences, 24, 1288-1301. 2011. 
SANTANA, Taís Profeta; OLIVEIRA, Yuri Lopes. Os benefícios da Responsabilidade Social Empresarial: uma análise em organizações no município baiano de Vitória da Conquista. Cadernos de Ciências Sociais Aplicadas, v. 21, p. 85-97, 2016.

SEBRAE. Responsabilidade social empresarial. Ebook. Editora Sebrae. 2017. Disponível em: https://eadlms.sebrae.com.br/main/novosebrae/media/dashboard?Culture=pt-BR\&codigoMedia=923 Acesso em: 23 de abril de 2020.

STADLER, Adriano et al. Empreendedorismo e responsabilidade social. Curitiba: Edição 2. Editora Intersaberes. 2014.

SVĚTLÍK, J.; VAVREČKA, V. Word of mouse in the world of brands. In Marketing Identity 2016 - Brands we love - part II. Trnava: University of Ss. Cyril and Methodius in Trnava. 2016.

TILL, B. D.; NOWAK, L. I. Toward effective use of cause-related marketing alliances. Journal of Product \& Brand Management, 9(7), 472-484. 2000.

WOODSIDE, A. G.; WALSER, M. G. Construindo marcas fortes no varejo. Journal of Business Research, 60(1), 1-10. 2007. 